\title{
O ENSINO-APRENDIZAGEM DA GEOGRAFIA ATRAVÉS DO JOGO TRILHA ECOLÓGICA
}

\section{THE TEACHING-LEARNING OF GEOGRAPHY THROUGH THE GAME ECOLOGICAL TRAIL}

\author{
Raiany Priscila Paiva Medeiros NONATO ${ }^{1}$ \\ Marta Evânia Miguel da SILVA ${ }^{2}$ \\ Mônica Sebastiana Brito de $\mathrm{SÁ}^{3}$ \\ Maria Da Paz CAVALCANTE ${ }^{4}$
}

\begin{abstract}
Resumo: Este artigo é fruto de uma experiência de pesquisa envolvendo a construção e aplicação de um material de ensino numa turma de Ensino Fundamental, considerando a temática Meio Ambiente. Objetiva analisar o processo de ensino-aprendizagem da Geografia no $3^{\circ}$ ano dessa etapa de ensino, através da utilização de um jogo denominado de "Trilha Ecológica". Para tanto, utiliza-se da abordagem qualitativa, atuando com a pesquisa-ação e a pesquisa bibliográfica. Fundamenta-se teoricamente nas discussões em torno da prática docente e da utilização de jogos como uma ferramenta auxiliar no processo de ensino-aprendizagem nas aulas de Geografia. Os resultados revelam que a utilização do jogo Trilha Ecológica funcionou como uma ferramenta que favoreceu a aprendizagem dos alunos acerca da temática citada, ao estimular o trabalho em equipe, o diálogo entre os alunos e destes com a professora. Assim, o jogo se configurou como um recurso facilitador e motivador da aprendizagem, aliado ao lúdico, proporcionando ao aluno um aprendizado mais dinâmico. A utilização do jogo em sala de aula, pela dinamicidade que ele representa, é um contributo ao aperfeiçoamento da didática docente e da aprendizagem mais prazerosa para o aluno.
\end{abstract}

Palavras-chave: Jogo; Prática docente; Ensino-aprendizagem; Trilha Ecológica; Geografia.

\begin{abstract}
This article is the result of a research experience involving the construction and application of a teaching material in a class of Elementary School, considering the Environment theme. It aims to analyze the teaching-learning process of Geography, in the 3rd year of this teaching stage, through the use of a game called Ecological Trail. It was used the qualitative approach, acting with action research and bibliographic research. This, bases the discussions around the teaching practice and the use of games as an auxiliary tool in the teaching-learning process in the classes of this curricular component. The results show that the use of the Ecological Trail game worked as a tool that favored the students' learning, about the mentioned theme, when stimulating the teamwork, the dialogue between the students and these with the teacher; that the game was configured as a facilitator and motivator of learning, allied to the ludic, providing the student with a more dynamic learning. The use of the game in the classroom, for the dynamicity that it represents, is a contribution to the improvement of teaching didactics and a more learning pleasure for the student.
\end{abstract}

Keywords: Game;Teaching Practice; Teaching and learning; Ecological Trail; Geography.

\footnotetext{
${ }^{1}$ Geógrafa Licenciada. Mestranda pelo Programa de Pós-Graduação em Ensino (PPGE), da Universidade do Estado do Rio Grande do Norte (UERN), Campus Avançado de Pau dos Ferros/RN.

${ }^{2}$ Geógrafa Licenciada. Mestranda pelo Programa de Pós-Graduação em Ensino (PPGE), da Universidade do Estado do Rio Grande do Norte (UERN), Campus Avançado de Pau dos Ferros/RN.

${ }^{3}$ Bacharela em Direito. Geógrafa Licenciada. Mestranda pelo Programa de Pós-Graduação em Ensino (PPGE), da Universidade do Estado do Rio Grande do Norte (UERN), Campus Avançado de Pau dos Ferros/RN.

${ }^{4}$ Doutora em Educação. Professora no Departamento de Educação e no Programa de Pós-Graduação em Ensino (PPGE/CAMEAM/UERN).
} 


\section{Introdução}

A prática docente envolve uma gama de conhecimentos e estratégias didáticas para que o aluno possa aprender da melhor maneira possível. Nesse ínterim, a educação brasileira utiliza documentos bases que norteiam a prática pedagógica, o planejamento e os conteúdos a serem ensinados em cada uma das etapas da educação básica. Esses documentos reúnem referenciais que direcionam os estados e municípios a proporcionarem uma formação comum aos alunos.

A exemplos dos documentos curriculares que orientam a educação brasileira, tem-se a Base Nacional Comum Curricular (BNCC), o mais novo documento que integra a política curricular educacional, que traz uma densa relação de conteúdos específicos, habilidades e competências para cada componente curricular.

No Ensino Fundamental I, os conteúdos devem desenvolver na criança a capacidade de começar a ler e compreender o mundo, através do domínio da escrita, da leitura e do cálculo. No tocante à Geografia, dentre as questões centrais, os conteúdos deste componente curricular contribuem para o raciocínio espacial e interpretativo do território e das paisagens do nosso cotidiano.

Durante o processo de ensino-aprendizagem, o professor precisa pensar sua prática para realizar um ensino que contemple a realidade, as coisas cotidianas e as vivências de seus alunos, relacionando-as aos conhecimentos científicos, de maneira que os alunos tornem estes conhecimentos significativos, para então compreenderem o mundo à sua volta. Assim, as ferramentas para a prática docente nos anos iniciais do Ensino Fundamental são diversas, dentre as quais podemos destacar os jogos que se tornam um dos aliados substanciais para o trabalho com os conteúdos em sala de aula. Essa ferramenta adquire um caráter didático capaz de proporcionar ao professor e ao aluno uma atividade prazerosa, através de regras e metas estabelecidas, de maneira a permitir a espontaneidade dos envolvidos para o alcance da sua aprendizagem.

A discussão acerca da utilização do jogo no processo de ensino-aprendizagem se faz necessária, tendo em vista o potencial educativo que essa ferramenta didática dispõe. Podemos destacar que o jogo desenvolve o raciocínio lógico e impulsiona o desenvolvimento de habilidades que podem ser trabalhadas em grupo, através da interação entre alunos e desses com o professor.

No desenvolvimento deste trabalho nos referenciamos em: Tardif (2011), na discussão sobre saberes e prática docente; em Callai (2005), na pauta sobre ensino de conteúdos da Geografia nos anos iniciais, em Kishimoto (2011), para tratar dos jogos e dos sentidos que estes representam dentro de cada contexto de aplicação, em Silva e Gomes (2010) e em Verri e Endlich (2009), para discorrer sobre o uso de jogos pedagógicos no ensino de Geografia, bem como em Oliveira e Pires (2010) no sentido de comentar sobre as possibilidades do uso de jogos como um recurso para a melhoria do processo de ensino-aprendizagem em Geografia.

Assim, este artigo objetiva analisar o processo de ensino-aprendizagem da Geografia, no $3^{\circ}$ (terceiro) ano do Ensino Fundamental, através da utilização de um jogo denominado de Trilha Ecológica. Caracteriza-se como uma abordagem qualitativa e o estruturamos envolvendo a prática docente do pedagogo; o jogo como recurso pedagógico para o ensino de Geografia e a aplicação do jogo Trilha Ecológica como ferramenta no ensino desse componente curricular na turma citada. 


\section{A prática docente do(a) Pedagogo(a) no Ensino da Geografia}

Mediar o conhecimento é algo desafiador para o professor, uma vez que envolve uma complexidade de teorias, conteúdos e metodologias, além dos vários desafios que existem dentro e fora do espaço da sala de aula. Para cada etapa de ensino da educação básica brasileira, são estabelecidos objetivos específicos para a prática docente e para a aprendizagem dos estudantes. Esses objetivos devem estar aliados aos componentes curriculares e às habilidades e competências a serem desenvolvidas ao longo de cada etapa da vida escolar dos estudantes.

Ao considerarmos que o conhecimento é algo a ser apreendido, para mediá-lo, é imprescindível a interação do professor com cada aluno envolvido no processo de ensinoaprendizagem, pois, conforme Tardif (2011, p. 129): “embora ensinem a grupos, os professores não podem deixar de levar em conta as diferenças individuais, pois são os indivíduos que aprendem, e não os grupos". Por esse ângulo, podemos perceber a importância de o professor conhecer as turmas onde trabalha, conhecer cada aluno e suas particularidades.

Para um processo de ensino-aprendizagem de qualidade, além de se fazer indispensável que o docente esteja munido de conteúdos, conceitos e habilidades necessárias para se trabalhar com os alunos, é fundamental que o docente possa refletir sobre sua prática e sobre a forma como os alunos estão apreendendo os conhecimentos. Neste sentido, a reflexão em torno da prática e das ferramentas utilizadas para mediação dos conteúdos são essenciais para um ensino-aprendizagem eficaz.

Nessa direção, abordar o conceito de professor reflexivo, em conformidade com Alarcão (2011, p. 44) nos parece propício, uma vez que essa autora afirma que essa noção "baseia-se na consciência da capacidade de pensamento e reflexão que caracteriza o ser humano como criativo e não como mero reprodutor de ideias e práticas que lhe são exteriores". Também no sentido da reflexão docente e coletiva entre os agentes educadores, Cavalcanti (2011, p. 88) afirma que "a reflexão coletiva na escola ajuda a mudar práticas já constituídas e consolidadas, ajuda a dar mais vida ao espaço e às rotinas escolares na medida em que pode desencadear ações dos sujeitos mais voltadas às necessidades demandadas". Por isso, acreditamos que o docente ao pensar constantemente seus métodos de ensino, sua formação e os resultados de sua prática, estará buscando aprimorar seu trabalho docente de maneira a aperfeiçoar o uso de metodologias e técnicas diferenciadas para possibilitar uma melhor aprendizagem aos alunos.

Ao acreditarmos que as especificidades de cada aluno devem ser consideradas pelo professor no processo de ensino, estamos tratando de uma prática docente qualificada, pautada na interação professor-aluno, na qual o docente planeja suas aulas e as realiza na perspectiva de que cada sujeito possa compreender e assimilar a sua realidade. Neste seguimento, concordamos com Tardif (2011, p. 118) que aponta:

Ao entrar na sala de aula, o professor penetra em um ambiente de trabalho constituído de interações humanas. As interações com os alunos não representam, portanto, um aspecto secundário ou periférico do trabalho dos professores: elas constituem um núcleo e, por essa razão, determinam ao nosso ver, a própria natureza dos procedimentos e, portanto, da pedagogia.

No campo pedagógico, a prática do profissional da educação deve ser dinâmica, no sentido de tornar a aprendizagem interessante e capaz de proporcionar uma relação de partilha e de conhecimento entre professor e aluno. O aluno é o sujeito que está em desenvolvimento e diante dessa responsabilidade a prática docente se apresenta complexa. Essa complexidade se torna mais forte quando entendemos que o aluno na contemporaneidade precisa portar uma 
criticidade embasada em conhecimentos científicos, frente às inúmeras informações que circulam por meio das redes de informação que são facilmente acessíveis para a grande massa. Dessa forma, reafirmamos a necessidade da reflexão constante do docente sobre e espaço escolar e principalmente sobre sua prática dentro da perspectiva das relações que se desenvolvem entre os alunos e entre os outros atores envolvidos no processo de ensinoaprendizagem.

Os alunos possuem intentos que fogem ao mundo que a escola está proporcionando, daí a dificuldade de alguns se identificarem com o espaço escolar e o tipo de atividade que o professor está propondo para ele. Logo, é requerido que o docente desenvolva uma reflexão sobre sua prática, que tenha uma formação consistente diante de desafios enfrentados no cotidiano de sua profissão. Nesse sentido, corroboramos com Herbertz (2014, p. 132), que afirma:

É imprescindível que seja dada a devida atenção aos aspectos de formação docente no que se refere às dimensões pedagógicas, ou seja, sobre os aspectos de aprendizagem. Há que se considerar o aluno como um ser holístico, com suas condições socioeconômicas e culturais, seu contexto histórico, sua história vital, suas ideias, seus sonhos, suas aspirações, seus sentimentos.

Para aperfeiçoar e desenvolver suas habilidades metodológicas, o docente necessita de oportunidade e de tempo para que possa exercer a reflexão sobre sua prática. Após a reflexão, é momento de estudar e buscar alternativas que favoreçam os resultados em sala de aula, oque envolve desde conhecer os alunos e ouvi-los, até o apreender as formas mais viáveis de mediar o conteúdo. Em seguida, é fundamental escolher o tipo de metodologia considerando a adequação à turma. É importante, também, compartilhar as experiências com outros docentes, pois é uma maneira de aprender junto com eles.

Refletindo, pesquisando e compartilhando ideias, o professor poderá encontrar meios para aperfeiçoar a mediação do seu trabalho e contextualizá-lo com a realidade dos alunos, que vivem em uma sociedade cada vez mais plural, global e tecnológica. Assim, percebemos que o professor pode ser um constante pesquisador de sua própria prática e essa tarefa é necessária.

Nos anos iniciais do Ensino Fundamental, a prática docente se dá através da atuação do(a) pedagogo (a) que, em sua formação inicial, teve oportunidade de apreender conteúdos específicos de cada uma das disciplinas que estão no currículo da Educação Básica. Dessa forma, os professores passam a adquirir alguns saberes sobre os componentes que irão ensinar e como ensiná-los. Juntamente a esses saberes, tem-se o conhecimento oriundo de reflexões entre o saber da matéria, os da educação e da didática, convencionado de "saber pedagógico" (PIMENTA, 1997 apud LIBÂNEO, 2010). Esses saberes são embasados por documentos que regulamentam o ensino dos conteúdos de cada componente curricular, a exemplo dos conteúdos da Geografia para os anos iniciais do Ensino Fundamental, que estão postos na Base Nacional Comum Curricular (BNCC), recente documento que passa a estruturar o currículo da Educação Básica.

Dos conteúdos de Geografia para os anos iniciais do Ensino Fundamental, a BNCC (2017) contempla, inicialmente, o desenvolvimento do pensamento espacial dos alunos, o que ocorre por meio de exercícios de localização geográfica, envolvendo gradativamente outros princípios metodológicos de raciocínio geográfico. Seguidamente, as crianças são orientadas a reconhecer e confrontar a realidade dos inúmeros lugares e suas diferenças, bem como a interação sociedade/natureza, dentre outras competências. 
Desse modo, inferimos que o docente para realizar sua prática de ensino no âmbito da Geografia, necessita portar conhecimentos científicos básicos que sustentam os conceitos geográficos e juntamente a isso dispor de metodologias que possibilitem a aprendizagem dos discentes. Nesse sentido, Azambuja (2011, p. 185) destaca que "a forma escolar do conhecimento científico se constrói a partir de fundamentos da Pedagogia e por meio de metodologias de ensino-aprendizagem que precisam ter coerência teórica e método". Posto isso, no ensino de Geografia proporcionar-se-á uma aprendizagem geográfica que comtemple o raciocínio lógico e espacial dos alunos nessa fase inicial de sua escolaridade, na qual passam a desenvolver, a partir de suas vivências e aprendizagens, a leitura e compreensão do mundo.

Apesar do objetivo central para os anos iniciais do Ensino Fundamental está centrado no desenvolvimento da capacidade da leitura e escrita, as crianças também devem ser orientadas a construir conceitos fundamentais para a sua vivência, a exemplo de alguns conceitos geográficos como espaço, território, região lugar e paisagem.

Callai (2005, p. 228) discute a possibilidade de aprender a Geografia nos anos iniciais do Ensino Fundamental, partindo da leitura do mundo, da vida e do espaço. A autora aborda a Geografia enquanto um componente curricular que tem como objetivo proporcionar a leitura e compreensão do espaço, compreendendo o sujeito como agente produtor do espaço geográfico, que está em constante transformação e que é fruto de ações e histórias acumuladas ao longo do tempo. Destaca ainda a importância da alfabetização espacial e cartográfica junto ao processo de alfabetização, onde a criança necessita aprender a ler e escrever as palavras junto à leitura e escrita do mundo.

A partir da afirmação da autora, compreendemos que a criança ao passo que aprende a ler e compreender o significado das palavras, também pode começar a ler e interpretar o mundo, à medida em que começa a perceber as paisagens, as distâncias, os espaços, os diferentes modos de viver em sociedade e passa a desenvolver as primeiras noções de espacialidade.

Nesse contexto, sobre o ensino de conteúdos da Geografia nos anos iniciais, Callai (2005, p. 236) afirma que "compreender o lugar em que se vive, encaminha-nos a conhecer a história do lugar e, assim, a procurar entender o que ali acontece". Diante disso, para mediar o processo de assimilação do conteúdo, de maneira que os alunos possam obter uma compreensão procedente, o (a) pedagogo (a) deve ter por base o conceito de "lugar" na Geografia e como esse componente curricular conceitua esse termo tão corriqueiro no vocabulário cotidiano das pessoas.

Os professores têm responsabilidade sobre a matéria que ensinam e sobre a forma como os alunos aprendem, assim, ciente de sua importante tarefa, o professor dos anos iniciais do Ensino Fundamental deve estar encarregado de dominar os princípios conceituais dos conteúdos disciplinares e fazer ligações didáticas à diferentes tipos de atividades, para conseguir uma aprendizagem consistente e que proporcione aos alunos raciocínio e problematização sobre o que está sendo estudado.

Para Callai (2005, p. 231), "a clareza teórico-metodológica é fundamental para que o professor possa contextualizar os seus saberes, os dos seus alunos, e os de todo o mundo à sua volta". Além disso, toda metodologia de ensino resulta em uma prática docente em que se pode obter bons resultados de aprendizagem ou não. Nesta perspectiva, Laterman (2010, p. 8) defende que "a prática pedagógica é parte da vida cotidiana dos professores. Tal prática tem as características da individualidade, que expressa, simultaneamente, um tempo/espaço social". Dessa maneira, é importante que a prática docente esteja fundamentada no saber pedagógico, embasada em conceitos e teorias, métodos e técnicas, que proporcione aos alunos a construção e o desvelamento do conhecimento. 
Das inúmeras técnicas de ensino que a didática nos apresenta, temos o jogo que há algum tempo vem sendo utilizado como instrumento de mediação para o processo de ensinoaprendizagem. O jogo é valorizado como instrumento de educação para ensinar conteúdos, podendo ser utilizado em qualquer etapa de ensino, desde a Educação Infantil até o Ensino Médio. Nesse ínterim, trataremos a seguir da relevância do jogo como instrumento utilizado pelo pedagogo (a) no ensino dos conteúdos da Geografia.

\section{O jogo como um recurso didático para o Ensino de Geografia}

Considerando que vivemos um momento em que diferentes formas de comunicação, de tecnologia e de metodologias são evidenciadas, a escola não pode se distanciar desse contexto, pois ela precisa se adequar e buscar maneiras de dinamizar o seu papel, a fim de mostrar que o conhecimento tem um valor significativo e que pode ser utilizado para entender uma infinidade de coisas e acontecimentos.

O processo de ensino-aprendizagem dispõe de uma diversidade de metodologias que podem ser utilizadas como recurso pedagógico. Neste aspecto, o jogo aparece como uma possibilidade de contextualizar os conteúdos e aproximá-los do cotidiano dos alunos, principalmente pelo fato dos jogos já fazerem parte de suas vidas desde a infância, a exemplo, do futebol, da queimada, da amarelinha, do xadrez, das advinhas, do quebra-cabeça, dos jogos de tabuleiro e dos jogos eletrônicos (disponíveis para serem jogados em computadores, tablets e celulares, em evidência na contemporaneidade).

Kishimoto (2011, p. 19) trata sobre a ideia de considerar que o jogo possui um sentido dentro de cada contexto em que se apresenta:

Considerar que o jogo tem um sentido dentro de um contexto significa a emissão de uma hipótese, a aplicação de uma experiência ou de uma categoria fornecida pela sociedade, veiculada pela língua enquanto instrumento de cultura dessa sociedade. [...] dessa forma, enquanto fator social, o jogo assume a imagem, o sentido que cada sociedade lhe atribui. É este o aspecto que nos mostra por que, dependendo do lugar e da época, os jogos assumem significações distintas.

Os jogos então assumem diferentes significados ao longo do tempo histórico e assim, atualmente podem ser utilizados como um recurso pedagógico facilitador do processo de ensino-aprendizagem. Deste modo, os jogos podem representar possibilidades de aprendizagem tanto para o professor, quanto para o aluno, desde que haja um planejamento prévio, com a definição do conteúdo, a escolha do tipo de jogo, objetivos, materiais e regras.

Considerando, que a potencialidade dos jogos apresenta raciocínios organizacionais na ordem de seus comandos para atingir os fins próprios, se faz necessário a compreensão dos graus de dificuldades dos mesmos, do conteúdo, da dinâmica utilizada para a evocação do conhecimento prévio e/ou ainda a garantia de atingir os objetivos propostos com fins educativos (apropriação de conceitos, valores, habilidades e atitudes) (SILVA e GOMES, 2010, p. 28).

“A existência de regras em todos os jogos é uma característica marcante, há regras explícitas como no xadrez ou amarelinhas, regras implícitas como na brincadeira de faz de conta, em que a menina se faz passar pela mãe que cuida da filha" (KISHIMOTO, 2011, p. 27). Levando em consideração a necessidade de estabelecimento de regras para a convivência 
em sociedade, os jogos são uma ferramenta educacional viável, pois além de representar oportunidades para lidar com a brincadeira e com a superação de desafios, eles contribuem para o desenvolvimento de limites, possibilidades e cooperação entre os sujeitos.

Participar de jogos educativos pode instigar o aluno a desenvolver a criação de estratégias para vencer os desafios, trabalhar os limites da convivência em grupo, a sensibilização de que há momentos em que é preciso ouvir, momentos em que é preciso falar, momentos em que é preciso conversar com outro para se chegar a um consenso ou para obter uma resposta sobre um problema que é comum à várias pessoas ou grupos sociais.

De acordo com Verri e Endlich (2009), o jogo não pode ser aplicado apenas como passatempo, é preciso levar em consideração o nível de conhecimento, a dinâmica e o grau de utilidade que ele pode proporcionar para professores e alunos. O jogo está carregado de um universo de limites e possibilidades, que dependem dos objetivos traçados e do que se pretende alcançar com sua aplicação, podendo ser utilizado em qualquer momento. A depender das habilidades que se pretenda desenvolver nos alunos, a utilização desse recurso pode favorecer o exercício de atividades de leitura, memorização de conteúdos, sensibilização, desenvolvimento de responsabilidade e trabalho em equipe. Nas palavras de Silva e Gomes (2010, p.14):

Os jogos são caracterizados como um tipo de recurso didático educativo que podem ser utilizados em diferentes momentos, como na apresentação de um conteúdo, avaliação de conteúdos já desenvolvidos e como revisão e síntese de conceitos importantes. Dentre as suas habilidades estão à concentração, o raciocínio, a interatividade, a cooperação em grupo, a resolução de problemas, atitudes que são fundamentais para o processo de aprendizagem.

É notório também, que esta ferramenta educativa contribui com a interação entre aluno e professor, bem como pode desenvolver uma postura reflexiva tanto na prática docente, a partir do momento em que o professor se propõe a estudar e desenvolver novas dinâmicas no ambiente escolar, quanto no tocante à forma como o aluno está fazendo apreensão do conhecimento. Os jogos "podem ser usados como meios auxiliares na superação de dificuldades de aprendizagem e maior envolvimento dos alunos com o objeto de estudo" (SILVA; GOMES, 2010, p. 11).

Além do mais, convém destacar que os jogos devem ser utilizados como instrumentos de apoio, de forma que esses sejam ferramentas úteis para a construção e aprofundamento do conhecimento dos conteúdos (SILVA; GOMES, 2010). Assim, eles não substituem sob hipótese alguma, o papel do professor, mas reafirmam a necessidade de uma prática docente mais interativa e dinâmica. No Ensino Fundamental I, eles também podem contribuir com o desenvolvimento da leitura e da escrita.

E a Geografia, enquanto disciplina, favorece ao aluno compreender o mundo e a realidade espacial sob a qual está inserido, por meio dela.

[...] nas aulas dos anos iniciais do ensino fundamental, podemos encontrar uma maneira interessante de conhecer o mundo, de nos reconhecermos como cidadãos e de sermos agentes atuantes na construção do espaço em que vivemos. $\mathrm{E}$ os nossos alunos precisam aprender a fazer as análises geográficas. E conhecer o seu mundo e o lugar em que vivem [...]. (CALLAI, 2005, p. 45).

Visto que a Geografia está embasada numa gama de conhecimentos que envolvem o espaço geográfico, ela possui uma ampla relação com o cotidiano dos alunos e é por isso que aproximá-la dos fenômenos que eles visualizam no dia a dia é de grande importância para 
tornar este conhecimento escolar significativo. Esta perspectiva pode se efetivar a partir da inovação de práticas pedagógicas que motivem o interesse dos alunos pelo aprender. Os jogos, então, podem ser uma alternativa de motivação que desperta o interesse dos alunos e possibilita o aprender brincando e se divertindo. Seguindo essa ideia, Oliveira e Lopes (2016, p. 173) destacam duas funções primordiais dos jogos:

Pode-se depreender, portanto, que o jogo possui duas funções: a primeira seria a função lúdica, um brincar livre e prazeroso, e a segunda seria sua função educacional, um brincar direcionado para um tema específico e com objetivos de aprendizagem. Essa integração das funções deve ser alcançada criativamente pelo docente ao organizar um ambiente rico e dinamizador das interações.

É nesse sentido que a Geografia Escolar tem um potencial para agregar um trabalho com os jogos, pois esse recurso pode representar maneiras de compreender a espacialidade e a complexidade dos fenômenos que ocorrem na superfície terrestre. Eles podem ser elaborados ou confeccionados para atender as necessidades de aprendizagem dos alunos, tanto para contextualizar um conteúdo trabalhado em sala de aula, quanto para reforçar e fixar conteúdos já estudados. Verri e Endlich (2009, p. 67) intercedem à favor deste recurso, pois:

Por meio do jogo, liberam-se tensões, desenvolvem-se habilidades, criatividade, espontaneidade, o indivíduo acaba jogando não como uma obrigação, mas como algo livre. Surge, pois, o prazer. É nesse aspecto que o professor de Geografia não deve ignorar ou desaproveitar. Empregando o jogo ao conteúdo adequado, os alunos poderão trabalhar em situações altamente motivadoras, principalmente quando aplicado a conteúdos de difícil assimilação.

Os jogos além de auxiliarem na compreensão de temáticas relacionadas à Geografia e desenvolverem habilidades, podem proporcionar o exercício de diferentes atividades, tais como: a apreensão de conteúdos e dados, comparação de realidades de diferentes nações do mundo, interpretação de dados quantitativos, apreensão de conceitos, sensibilização em torno de questões relacionadas ao cotidiano dos alunos, distribuição de elementos físico-naturais sobre a superfície terrestre, espacialização de fenômenos naturais e sociais, dentre outros. Oliveira e Lopes (2016, p. 173) chamam a atenção para a ideia de que os jogos devem oportunizar a apreensão de conceitos, habilidades e valores que evidenciem a importância da educação geográfica na atualidade. "O desafio sempre será articular as possibilidades do jogo àquelas habilidades geográficas que se quer, por meio dele, desenvolver nos alunos" (OLIVEIRA e LOPES, 2016, p. 174).

Nesta perspectiva, discutiremos a seguir sobre o jogo denominado Trilha Ecológica, desenvolvido em uma turma de $3^{\circ}$ ano do Ensino Fundamental, em uma escola pública da rede estadual de ensino do Rio Grande do Norte, como uma ferramenta auxiliar para o processo de ensino-aprendizagem a partir do tema Meio Ambiente. Por meio desse material didático analisamos a eficácia da metodologia com jogos a partir da prática de uma pedagoga no Ensino Fundamental I.

\section{Material e métodos}

Ao considerarmos os jogos como uma ferramenta do processo de ensinoaprendizagem, pensamos a pesquisa com um jogo que auxiliasse no ensino de conteúdos da 
Geografia e que pudéssemos analisar a eficácia da metodologia de ensino empregada. Nesse sentido, consideramos ser importante, antes da aplicação em sala de aula, que o material correspondente ao jogo fosse pensado e desenvolvido tanto com uma contribuição para com o aprendizado do alunado como favorecedora da prática docente.

Foi sob essa perspectiva que nós, discentes do Programa de Pós-Graduação em Ensino (PPGE) da Universidade do Estado do Rio Grande do Norte (UERN), do Campus Avançado Professora Maria Elisa de Albuquerque Maia (CAMEAM), para requisito de avaliação do Componente Curricular "Produção e Avaliação de Materiais de Ensino", realizamos uma atividade de produção de materiais didático-pedagógicos que foram aplicados em uma sala de aula da Educação Básica.

Como uma das discentes deste componente curricular é professora efetiva da rede estadual de ensino no Estado do Rio Grande do Norte, e parte do grupo era composto por geógrafas licenciadas, pensamos em desenvolver um jogo que pudesse vir a ser utilizado como um recurso didático para o processo de ensino-aprendizagem de conteúdos da Geografia nos anos iniciais do Ensino Fundamental, na turma que essa professora ensina.

Percorremos um caminho teórico-metodológico com a abordagem qualitativa e utilizamos a pesquisa-ação (dentre outros aspectos, pela possibilidade de interação entre pesquisadores e sujeitos colaboradores) e a pesquisa bibliográfica a qual fundamenta as discussões em torno da prática docente e da utilização de jogos como uma ferramenta auxiliar ao processo de ensino-aprendizagem nas aulas de Geografia.

Para a realização da pesquisa escolhemos uma turma do $3^{\circ}$ ano do Ensino Fundamental I, de uma escola pública da rede estadual de ensino do Rio Grande do Norte localizada na cidade de Rafael Fernandes, Alto Oeste Potiguar.

Quanto à definição do conteúdo geográfico que seria abordado no jogo, a escolha se deu em razão de a professora estar trabalhando com a temática o Meio Ambiente. Consideramos ser ela relevante para a formação de cidadãos e definimos que seria desenvolvido um jogo envolvendo essa temática. Em seguida, passamos à reflexão sobre a qual modalidade de jogo seria utilizada e, por se tratar de crianças com idades entre 7 (sete) e 8 (oito) anos, optamos por construir um jogo de trilha que foi intitulado de Trilha Ecológica.

Os jogos de trilha são comuns entre as brincadeiras de criança. Eles geralmente são tabuleiros em que cada jogador é representado por um peão, deve-se jogar dados e, de acordo com o número que alcançou com o lançamento dos dados, conduzir seu peão pelas "casas" do jogo; sendo o ganhador aquele que primeiro alcançar a linha de chegada. Foi partindo dessa ideia que a Trilha Ecológica foi construída. Todavia, a fim de dinamizar mais ainda o jogo, ele foi construído em tamanho real para que os alunos fossem os próprios peões.

Salientamos que o jogo foi pensado e organizado com antecedência, de acordo com os conteúdos e objetivos da sequência didática elaborada pela professora da turma que tinha como título "Vamos cuidar do Meio Ambiente". Essa sequência didática teve como conteúdos: Reciclagem, Meio Ambiente, Poluição, Água, Lixo e Saneamento Básico. Como objetivos foram elencados: conhecer o conceito de Meio Ambiente; perceber a importância de preservar o ambiente em que vivemos; conhecer as formas de colaborar com a diminuição da produção de lixo; compreender as formas de descarte adequado de lixo; observar que as ações humanas interferem na qualidade do ambiente; evidenciar a poluição do Meio Ambiente e o que o homem faz para modificar essa situação; analisar se a cidade/rua em que residem os alunos tem saneamento básico; sensibilizar os alunos e seus familiares sobre a importância de evitar o desperdício de água e o descarte de lixo em local inadequado.

Para a construção do jogo foram utilizamos materiais como tecido TNT, folha de EVA emborrachada, pincéis coloridos, cartolina para a confecção do dado, além de cola e tesoura. Vejamos a seguir (figura 1) a trilha confeccionada: 
Figura 1: Processo de construção do jogo.



Fonte: Sá (2018).

Dando sequência ao processo, tivemos a explicação de conteúdo e a realização de atividades que ficou sob a responsabilidade da professora da turma. Por fim, ocorreu a aplicação do jogo, no dia 28 de agosto de 2018, com a presença de 13 alunos.

\section{Resultados e discussões}

Os jogos são fundamentais para o desenvolvimento da criança devido ao universo de possibilidades que eles podem oferecer, desde o movimentar-se, o desenvolvimento do raciocínio, da atenção, o trabalho em equipe, dentre outras habilidades que variam de acordo com a modalidade de jogo. Na educação, os jogos podem ser uma ferramenta viável para o processo de ensino-aprendizagem, a partir da dinamicidade das aulas e da aproximação entre o aprender e o brincar.

Durante o planejamento da atividade, foram estabelecidos pela professora alguns objetivos a serem alcançados com o jogo, dentre eles destacamos: sensibilizar os alunos para a necessidade minimizar os desperdícios de água e energia; abordar de fenômenos que causam impactos ao Meio Ambiente e prejuízo à qualidade de vida, como as queimadas e o descarte de lixo em áreas de rios e lagoas.

Ao longo do processo da pesquisa, percebemos o comprometimento da professora com o planejamento e com a melhor forma de adequar o conteúdo de Geografia estudado pelos alunos à realização do jogo. Além disso, ela mostrou domínio sobre o conteúdo, bem como, o contextualizou com a vivência de seus alunos, como podemos mencionar quando ela buscou discutir sobre o que eles conseguiam visualizar na paisagem local como prejudicial ao Meio Ambiente. Ocasião em que os alunos citaram: "as queimadas que prejudicavam a vida dos animais, das plantas e dos seres humanos; o lixo jogado em locais inadequados, como nos esgotos e nos rios". Compreendemos, assim, que nessa atividade foi fundamental mostrar que o conhecimento geográfico tem um valor significativo e pode ser utilizado para interpretar o que se visualiza no espaço onde se está inserido. 
Para a aplicação do jogo, a turma foi dividida em dois grupos de alunos e, em seguida, um aluno de cada equipe foi sorteado para ser o "peão" da sua equipe. Para que os conteúdos de Geografia fossem trabalhados de forma efetiva durante a aplicação do jogo, a professora elaborou perguntas sobre o conteúdo Meio Ambiente, para que, ao longo do percurso, os alunos fossem respondendo-as, das quais destacamos: "O que é Meio Ambiente?" "Por que provocar queimada é perigoso?" "Porque as chuvas causam enchentes na cidade?" "Quantos anos o chiclete leva para se decompor na natureza?" "Quais são as três atitudes que podemos ter em casa para contribuir com a preservação da natureza?". "Quais atitudes diárias podem ser tomadas para economizar água?”. Além das perguntas, algumas casas da Trilha Ecológica, traziam lembretes que buscavam sensibilizar os alunos no tocante aos cuidados com o Meio Ambiente: "Economize energia! Volte uma casa". "As árvores fazem bem para os seres vivos do nosso planeta. Pule duas casas". "Não faça queimadas, nem desmatamento. Volte duas casas".

Assim, caso os alunos respondessem a pergunta corretamente, poderiam avançar na Trilha Ecológica, visando alcançar a linha de chegada, porém se errassem, voltavam para a casa anterior à última jogada. A equipe vencedora era aquela que chegasse primeiro à linha de chegada. Foram realizadas um total de 4 (quatro) rodadas, com o objetivo de que o máximo de alunos participassem efetivamente do jogo.

Destacamos que antes e durante a aplicação do jogo os alunos se mostraram bastante entusiasmados, participando de maneira satisfatória, respondendo prontamente às perguntas acerca do tema Meio Ambiente e demonstrando que já praticavam, tanto dentro do ambiente escolar quanto fora dele, ações que visavam o uso sustentável do ambiente. A seguir, podemos visualizar o momento da organização das equipes e da explicação das regras do jogo (figura 2):

Figura 2: Momento da organização das equipes.

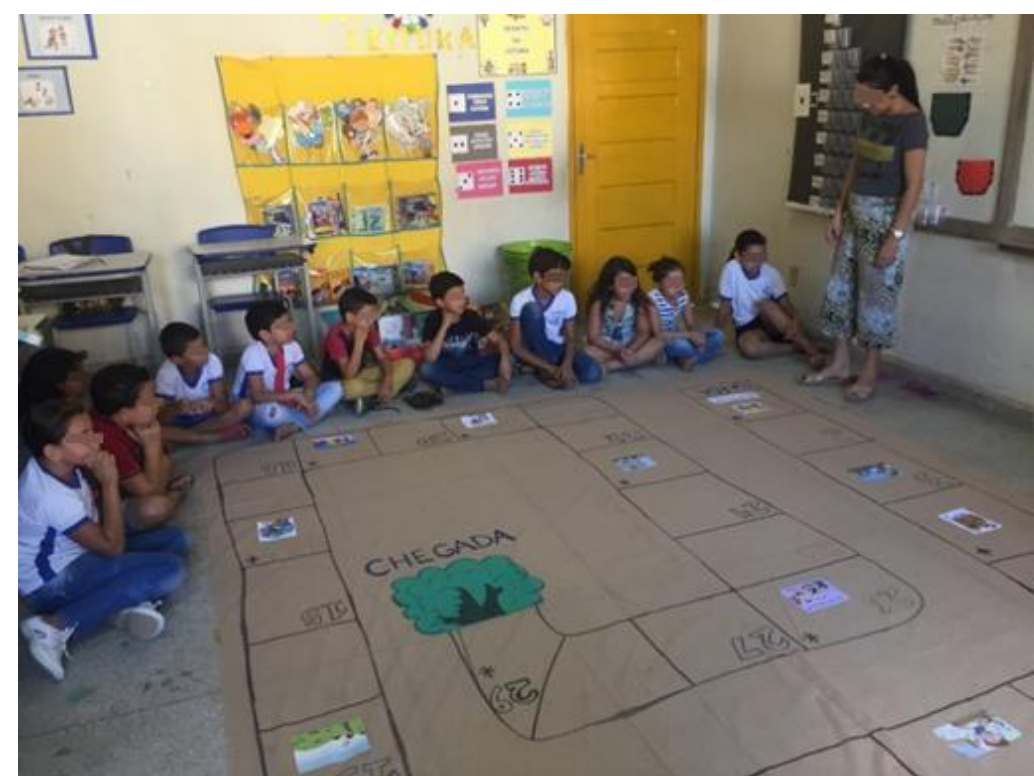

Fonte: Sá (2018).

As perguntas realizadas durante o jogo traziam em algumas casas da Trilha Ecológica, elementos que direcionavam a resposta correta, bem como, sensibilizavam os alunos no tocante a alguma prática diária realizada por eles, a exemplo, do cuidado para não deixar a torneira aberta, enquanto se escova os dentes, ou o chuveiro ligado, enquanto se ensaboa o corpo, a luz acesa sem necessidade, a mortalidade de peixes diante do lixo jogado nos rios, 
dentre outras questões, representadas por imagens. Consideramos importante destacar que cada uma das perguntas foi elaborada pela professora, com base nas atividades e nas discussões realizadas ao longo das aulas. Observemos o momento de realização das perguntas na figura 03 .

Figura 3: Momento em que perguntas eram feitas a uma das participantes

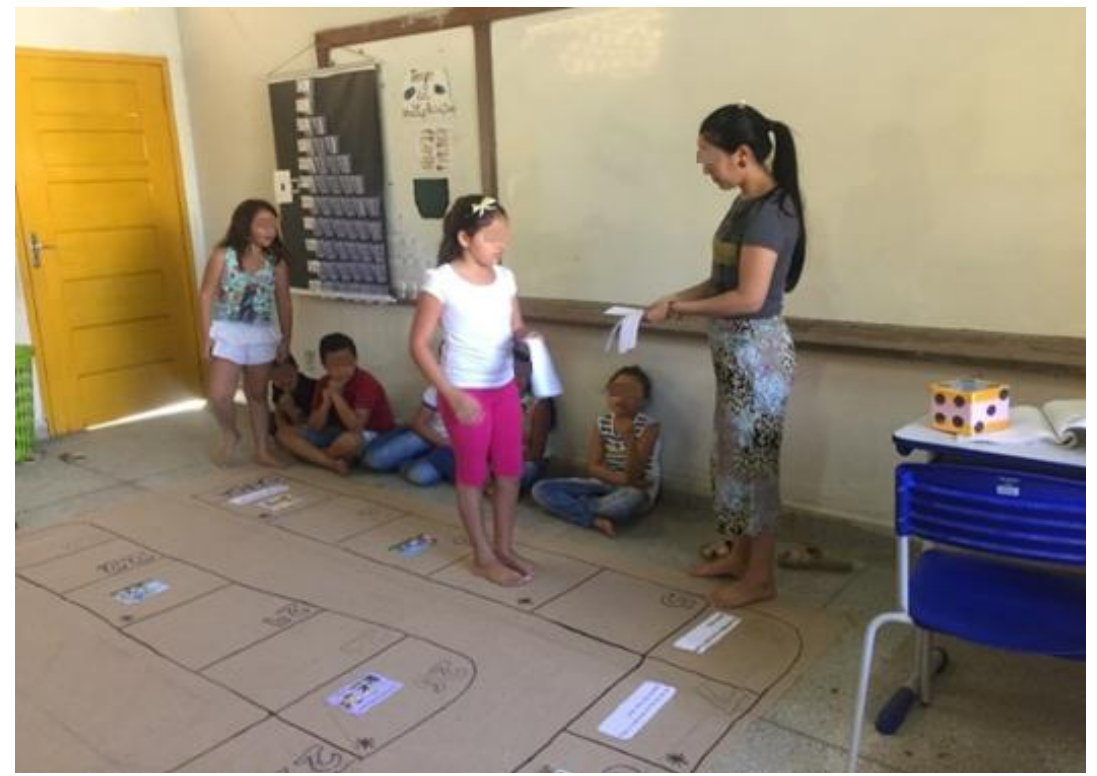

Fonte: Sá (2018).

No momento da aplicação do jogo foi possível percebermos que alguns dos alunos participantes já tinham o domínio do conteúdo, pois respondiam prontamente o que lhes era perguntado, principalmente quando relacionado ao que eles visualizavam no seu cotidiano, como as queimadas ou questões que poderiam minimizar impactos ao ambiente e à vida, como o uso racionado da água.

Uma das regras era que o aluno, representante da equipe - o peão - precisava discutir junto com os demais colegas qual seria a resposta correta, à medida em que os alunos conversavam sobre a resposta, possibilitavam que o conteúdo estudado fosse discutido e reforçado.

A Trilha Ecológica proporcionou um momento em que os alunos estavam livres para movimentar-se pelo tabuleiro, da forma como desejassem. Os peões à maneira que avançavam no percurso, pulavam e brincavam sobre a trilha, e assim era visível a diversão e alegria deles com a atividade.

Observamos que os alunos desempenharam com eficácia a tarefa de responder as perguntas com a ajuda dos demais colegas, realizando de fato um trabalho em equipe. Com isso, a empolgação e o desejo de aprender se intensificava, afinal o objetivo era percorrer a trilha até o final para poder vencer o jogo, mas antes, para isso precisavam aprender o conteúdo e responder corretamente as perguntas.

Averiguamos que as imagens espalhadas pelas "casas" da trilha auxiliavam os alunos que ainda não detinham um domínio total do conteúdo a elaborar suas próprias respostas e a aprenderem mais sobre a temática estudada, pois essas traziam lembretes sobre o uso racionado da água e energia, impactos sobre o descarte inadequado do lixo, como enchentes e mortalidade de peixes.

A interação entre os alunos e destes com a professora foi outro fator bastante favorável à aprendizagem, visto que esses não hesitavam em colocar suas dúvidas. E se não entendiam a 
pergunta, pediam para que a professora esclarecesse, assim como, ela também intervia, em vários momentos, contribuindo com reflexões e até mesmo fazendo complementações às respostas dos alunos. Foi um momento em que a docente também aproveitou para apoiar as tentativas dos alunos de responderem as perguntas, que em alguns momentos não estavam corretas.

Embora a professora não seja da área da Geografia, percebemos sua atenção em trabalhar um conteúdo carregado de conceitos geográficos, procurando explorá-los bem, a partir dos aspectos do lugar, dos aspectos físico-naturais e da realidade em que os alunos vivem, buscando fazer um paralelo com questões mais gerais, e digamos assim, mais globais relativas ao Meio Ambiente. Por conseguinte, consideramos que isso foi de grande importância para a aprendizagem em Geografia e para a compressão de mundo e do espaço geográfico.

Acreditamos que o fato de a professora já possuir o hábito de utilizar o jogo como uma ferramenta de auxílio para processo de ensino-aprendizagem, isso contribuiu para o sucesso efetivo da atividade realizada.

Destacamos também que ao longo da realização do jogo, ela desenvolveu um papel de mediadora do saber, uma vez que os alunos não eram meros personagens efêmeros, pelo contrário, eles protagonizaram a construção do próprio saber, uma vez que participaram de forma efetiva da realização da atividade.

A partir da análise e reflexão acerca da aplicação do jogo, constatamos que atrelar o lúdico à aprendizagem dos conteúdos desperta o interesse dos alunos, o que evidencia a eficácia da metodologia utilizada como uma ferramenta de auxílio ao processo de ensinoaprendizagem.

A utilização do jogo Trilha Ecológica veio, portanto, para enriquecer a didática de ensino da professora em sala de aula, mostrando-se como uma ferramenta metodológica eficaz no ensino da temática estudada, proporcionando dinamicidade e um maior aprendizado aos alunos.

Ressaltamos a importância, e até mesmo a necessidade de os docentes lançarem mão de atividades que estimulem o desejo de aprender e mostre como um determinado conteúdo pode ser utilizado para compreender, na prática, como se dão os fenômenos geográficos.

\section{Considerações finais}

Considerando a importância da prática do professor estar assentada em uma formação inicial e continuada, torna-se fundamental a constante busca por atualizações teóricometodológicas que deem conta das necessidades de aprendizagem dos alunos e da dinamização das práticas de ensino. Neste sentido, a utilização do jogo em sala de aula é muito útil, dada a possibilidade de dinamicidade que ele representa, é um contributo ao aperfeiçoamento da prática docente e da aprendizagem mais prazerosa para o aluno.

O jogo faz parte da realidade dos discentes e, nesse sentido, além de possibilitar a interação com o conteúdo de forma aplicável, favorece à compreensão e o desenvolvimento de habilidades no aluno.

O Jogo Trilha Ecológica proporcionou uma dinâmica muito interessante dentro da sala de aula, desenvolveu o trabalho em equipe, estimulou a troca de aprendizagem entre os alunos e promoveu o diálogo entre eles - à medida em que precisavam discutir juntos as respostas de cada pergunta. Ademais, promoveu também o entusiasmo com o estudo.

Outro fator relevante foi o fato de fazer com que os alunos entendessem a importância de incluir o outro nas decisões, o respeito e a escuta da fala do outro na construção das respostas. Discutir o tema Meio Ambiente é relevante para os espaços educacionais, 
principalmente porque é fundamental para a sobrevivência da espécie humana. Por isso, tratase tanto do conhecer como do sensibilizar os alunos sobre o preservar e o cuidar do ambiente natural, evitando desperdícios e impactos ambientais. Nesse sentido, averiguamos que os alunos passaram a se atentar mais para as questões que foram discutidas, assim como para com sua responsabilidade e atuação no meio em que vivem.

A partir desse trabalho, apresentamos os resultados de uma pesquisa com um viés de intervenção, realizada através da aplicação de um material de ensino em uma turma de $3^{\circ}$ Ano do Ensino Fundamental I. Nesta perspectiva, acreditamos oferecer uma contribuição para a dinamicidade das aulas de Geografia, a partir dos jogos e da potencialidade que esses trazem consigo para a mediação do conhecimento empírico e científico. Assim, consideramos a potencialidade que o jogo apresenta, desde que criteriosamente organizado, podendo ser utilizado para atingir diferentes objetivos, em qualquer nível de ensino, e servindo de base para a assimilação de conceitos, valores, habilidades e atitudes.

\section{Referências}

ALARCÃO, Isabel. Professor reflexivo em uma escola reflexiva. 8. ed. v. 8. São Paulo: Cortez 2011.

AZAMBUJA, Leonardo de. Metodologias cooperativas para ensinar e aprender Geografia. In: CALLAI, Helena Copetti (Org.), Educação geográfica: reflexão e prática. Ijuí: Ed. Unijuí, 2011, p. 185-210.

BNCC. Ensino Fundamental no contexto da Educação Básica. Brasília, 2017. Disponível em:http://basenacionalcomum.mec.gov.br/abase/\#fundamental/geografia. Acesso em setembro de 2018.

CALLAI, Helena Copetti. Aprendendo a ler o mundo: a geografia nos anos iniciais do Ensino Fundamental. Cad. Cedes, v. 25, n. 66, Campinas, 2005. p. 227-247 Disponível em:http://www.scielo.br/pdf/ccedes/v25n66/a06v2566.pdf. Acesso em setembro de 2018.

CAVALCANTI, Lana de Souza. A Geografia Escolar e a Sociedade Brasileira Contemporânea. In: TONINI, Ivaine Maria; GOULART, Ligia Beatriz; MARTINS, Rosa; CASTROGIONANNI, Antônio Carlos; KAERCHER, Nestor André (org.). O ensino de geografia e suas composições curriculares. Porto Alegre: Ufrgs, 2011. Pag. 78-94

HERBERTZ, Dirce Hechler. Diários de Aula: reflexões sobre a prática docente no ensino fundamental. Educação Por Escrito. v. 5, n. 1, Porto Alegre. p. 129-141, jan.-jun. $2014 . \quad$ Disponível em:http://revistaseletronicas.pucrs.br/ojs/index.php/porescrito/article/view/17388. Acesso em dezembro de 2018.

KISHIMOTO, Tizuco Morchida. O jogo e a educação. In: brincadeiras e a educação. São Paulo: Cortez, 2011. P. 18-47.

(Org) Jogos,

LATERMAN, Ilana. Ação docente nos anos iniciais do ensino fundamental: entre tantas possibilidades. Rev. Teoria e Prática da Educação,v. 13, n. 1. Florianópolis, SC, Jan./Abr. 2010. $\quad$ p. 5-18. Disponível em: http://periodicos.uem.br/ojs/index.php/TeorPratEduc/article/view/15315/8190. Acesso em setembro de 2018. 
LIBÂNEO, José Carlos. O ensino da Didática, das metodologias específicas e dos conteúdos específicos do ensino fundamental nos currículos dos cursos de Pedagogia. R. bras. Est. Pedag. V. 91, n. 229, Brasília set./nov. 2010. P. 562583. Disponível em: http://rbep.inep.gov.br/index.php/rbep/article/view/630/610.Acesso em setembro de 2018.

OLIVEIRA, Tais Pires.; LOPES, Claudivan Sanches. “Acertando as horas”: jogo cartográfico como recurso didático geográfico no ensino de fusos horários. Rev. Tamoios, São Gonçalo (RJ), v.12, n. 2, p. 171-189, jul/dez., 2016. Disponível em:https://www.epublicacoes.uerj.br/index.php/tamoios/article/view/25888. Acesso em dezembro de 2018.

SILVA, Julsimar Portela.; GOMES, Marquiana de F. Vilas Boas. Jogos pedagógicos para o estudo das florestas no ensino de geografia. In: O Professor PDE e os desafios da escola pública paranaense, v. I. Governo do Estado do Paraná, Secretaria da Educação. 2010. p.131. em:http://www.diaadiaeducacao.pr.gov.br/portals/cadernospde/pdebusca/producoes_pde/2010 /2010_unicentro_geo_artigo_julsimar_portela_da_silva.pdf. Acesso em setembro de 2018.

TARDIF, Maurice. Saberes docentes e formação profissional. 12 ed. Petrópolis, RJ: Vozes, 2011.

VERRI, Juliana Bertolino; ENDLICH, Ângela Maria. A utilização de jogos aplicados no ensino de Geografia. Revista Percurso: NEMO, São Paulo, v. 1, n. 1, p. 65-83, 2009. Disponível em:http://eduem.uem.br/ojs/index.php/Percurso/article/download/8396/4916. Acesso em agosto de 2018. 